\title{
Effects of Processing Parameters on Microstructure and Ultimate Tensile Strength of Thixoformed AM60B Magnesium Alloy
}

\author{
Ti Jun Chen*, Rui Quan Wang, Ying Ma, Yuan Hao \\ Key Laboratory of Gansu Advanced Nonferrous Metal Materials, \\ Lanzhou University of Technology, Lanzhou 730050, China
}

Received: November 2, 2011; Revised: May 29, 2012

\begin{abstract}
The effects of processing parameters, such as the punch speed, reheating duration and reheating temperature, on microstructure and ultimate tensile strength (UTS) of thixoformed AM60B magnesium alloy have been investigated. The results indicate that low punch speed, short reheating duration or low reheating temperature often produces the defect of cold shuts or shrinkage porosities. On the contrary, gas pores can easily form. In addition, the reheating duration or temperature also has obvious effects on the primary particle size, fraction and morphology. The three parameters can significantly affect the UTS due to their effects on the formation of pores (cold shuts, shrinkage porosities and gas pores). But they can not alter the fracture path during tensile testing and the path is always along the secondarily solidified structures between the primary particles. The effect of pore amount on the UTS is lager than that of the primary particle size, fraction or morphology. In view of their effects on the microstructure compactness and the resultant UTS, the optimized parameters are reheating for 130 minutes at $610{ }^{\circ} \mathrm{C}$ and punch speed of $3 \mathrm{~m} / \mathrm{s}$.
\end{abstract}

Keywords: AM60B magnesium alloy, thixoforming, microstructure, ultimate tensile strength

\section{Introduction}

Magnesium alloys have large potential in fabrication of structural components of automobiles due to their high specific strength ${ }^{1}$. In addition, they also have wide applications in the fields of electronic products, portable tools, sporting goods and aerospace vehicles ${ }^{2}$. However, the mechanical properties of most of them are relatively low compared with those of another family of light alloys, aluminium alloys, and can not match the requirements in many applications. It is well known that thixoforming, a relatively new metal forming technology, can significantly improve mechanical properties of aluminium alloys and a large number of thixoformed aluminum alloy components has been applied to automobiles ${ }^{3,4}$. So it is theoretically expected that thixoforming should be a promising way to improve the mechanical properties of magnesium alloys.

Unfortunately, the application of thixoforming on magnesium alloys is quite late compared with aluminum alloys and only one technique named thixomoulding has been commercially used ${ }^{4}$. It is surprised that the elongation of thixomoulded AZ91D magnesium alloy is obviously improved while its ultimate tensile strength is equivalent to or less than that of the traditional die casting or permanent mould casting alloy 5 . A query if magnesium alloys are adequate to be thixoformed is then arising. To clarify this problem, the relations between processing parameters, resultant microstructure and mechanical properties should be studied. But most of the existing investigations have focused on the formation of semisolid non-dendrititic

*e-mail: chentj1971@126.com microstructures ${ }^{6-10}$. Only a few papers have involved the microstructures and mechanical properties of thixoformed magnesium alloys under a given set of processing parameters ${ }^{11,12}$. Study on the detailed effects of processing parameters on microstructure (including casting defects) and mechanical properties has not been found.

Therefore, in this work, the effects of three main processing parameters, such as punch speed, reheating temperature and reheating time, on the microstructure, especially the pores resulted from insufficient filling, solidification shrinkage or gas, of thixo-die-casting AM60B magnesium alloy have been studied. Simultaneously, the ultimate tensile strength (UTS) of the formed alloy has also been examined and the corresponding relations between the parameters, microstructure and UTS have been discussed. It must be noted that the pressure and mould temperature are also two main parameters for thixo-die-casting, but their effects will be discussed in elsewhere and have not been included in this work.

\section{Experimental Procedure}

The material used in this work is a commercial AM60B magnesium alloy with a composition of Mg-5.98Al-0.343Mn-0.023Si (in wt. (\%)). AM60B alloy was first remelted in a resistance furnace and $1.2 \% \mathrm{MgCO}_{3}$ was added at $790{ }^{\circ} \mathrm{C}$ as grain refiner. After the $\mathrm{MgCO}_{3}$ completely reacted with the molten alloy (i.e., there was no gas to release), the melt was held for 10 minutes and then poured into a steel mould with room temperature. 
Repeating the above experimental procedures, some casting rods with dimensions of $\Phi 70 \mathrm{~mm} \times 150 \mathrm{~mm}$ were obtained. Then, the rods were machined into ingots with dimensions of $\Phi 70 \mathrm{~mm} \times 112 \mathrm{~mm}$ as the starting ingots for thixo-die-casting. The authors' previous investigation indicated that $\mathrm{MgCO}_{3}$ was an effective grain refiner for AM60B alloy and could decrease the grain size from $329 \mu \mathrm{m}$ of the unrefined alloy to $69 \mu \mathrm{m}^{13}$. A uniform semisolid microstructure with small (average size of $73 \mu \mathrm{m}$ ) and spheroidal (shape factor of 1.3) primary particles could be obtained after the refined alloy was partially remelted at $610{ }^{\circ} \mathrm{C}$. So $\mathrm{MgCO}_{3}$ is chosen as the grain refiner in this work in order to obtain a globular semisolid microstructure.

The starting ingots were heated for a time at a semisolid temperature in a resistance furnace, and then they were handled to the chamber of a DAK 450-54 die-casting machine and pressed in a punch speed. The mould temperature was kept at $200{ }^{\circ} \mathrm{C}$ when pressed. The detailed parameters are shown in Table 1. Namely, three thixoforming parameters such as punch speed, reheating temperature and reheating time were considered. One thixoformed product is shown by Figure 1. It indicates that three tensile bars can be obtained from each product.

As shown by Figure 1, the microstructures in three regions, marked by $\mathrm{A}, \mathrm{B}$ and $\mathrm{C}$ respectively, of a tensile bar formed at each specific condition were observed on a Mef-3 optical microscope. To examine the pores (formed from insufficient filling, solidification shrinkage and gas), the metallographic specimens were first observed without etching. Then they were etched using $4 \% \mathrm{HNO}_{3}$ aqueous



Figure 1. Photograph of the thixoformed AM60B alloy product under punch speed of $3 \mathrm{~m} / \mathrm{s}$.

Table 1. The detailed thixoforming parameters used in this work.

\begin{tabular}{lccc}
\hline Parameters & $\begin{array}{c}\text { Punch } \\
\text { speed } \\
(\mathbf{m} / \mathbf{s})\end{array}$ & $\begin{array}{c}\text { Reheating } \\
\text { time } \\
(\text { minutes })\end{array}$ & $\begin{array}{c}\text { Reheating } \\
\text { temperature } \\
\left({ }^{\circ} \mathbf{C}\right)\end{array}$ \\
\hline Punch speed & $1,3,5,7,9$ & 130 & 610 \\
\hline $\begin{array}{l}\text { Reheating } \\
\text { time }\end{array}$ & 3 & $90,110,130$, & 610 \\
\hline $\begin{array}{l}\text { Reheating } \\
\text { temperature }\end{array}$ & 3 & 150 & $600,605,610$, \\
615,620
\end{tabular}

solution to observe the other microstructure characteristics. The obtained images were analyzed by Image-Pro Plus 5.0 software. Three images with magnification of 100 times for each specimen were examined and the average values were taken as the specimen's pore percentage, primary particle size and primary particle fraction. Tensile testing was carried out on a DG-10T universal material testing machine at a nominal strain rate of $3.32 \times 10^{-3} \mathrm{~s}^{-1}$. For each forming condition, at least three bars were tested.

\section{Results and Discussion}

\subsection{Effect of punch speed}

Figure 2 shows the typical microstructures of region $\mathrm{B}$ in the thixoformed AM60B magnesium alloys under different punch speeds. It indicates that their microstructures are all composed of spheroidal primary particles and surrounding secondarily solidified matrix, belonging to a typical as-thixoforming microstructure. In view of the constituent morphologies, there is no obvious difference between them. The quantitative examination result indicates that the primary particle size and fraction are $85 \mu \mathrm{m}$ and 0.5 respectively for all of the formed alloys. It is expected that the thixoformed microstructure should be affected by reheating conditions prior to forming when the initial microstructure of starting ingot and solidification conditions after mould-filling are given. As known from the above section of experimental procedure, the initial microstructure, mould temperature, reheating temperature and reheating time are all kept at constants when the punch speed is changed. So the formed microstructure does not change with the punch speed.

But it must be noted that the mould-filling behavior has large effect on the final microstructure theoretically under specific conditions in view of deformation mechanisms of a semisolid ingot ${ }^{14,15}$. Under the present conditions, the deformation should operate in a flow of liquid incorporating solid particles because the liquid fraction is relatively high (about 0.5 ) and the deformation rates are also very high under all of the used punch speed conditions $(1-9 \mathrm{~m} / \mathrm{s})^{15}$. This mechanism not only does not generate liquid or solid segregation, but also does not lead the primary particles to plastically deform. The present result shows that there is no liquid or solid segregation and the primary particles do not deform (Figure 2), which is just consistent to the characteristics of this mechanism. So it can be suggested that the mould-filling has no effect on the final microstructure.

However, Figure 2 indicates that there are always more or less pores in all of the formed alloys and the punch speed has large effect on the pore size and amount. The pores distribute in the secondarily solidified matrix and they can be divided into two categories, occasionally distributed large-sized pores (marked by A) and uniformly distributed small-sized pores (marked by B). As the punch speed increases from $1 \mathrm{~m} / \mathrm{s}$, the numbers and sizes of these two kinds of pores all decrease (comparing Figure $2 \mathrm{a}, \mathrm{b}$ ). Pores A basically disappear when the speed increases to $3 \mathrm{~m} / \mathrm{s}$ and only a small number of pores B exist (Figure 2b). But when the speed exceeds $3 \mathrm{~m} / \mathrm{s}$, pores A appear again and the total 


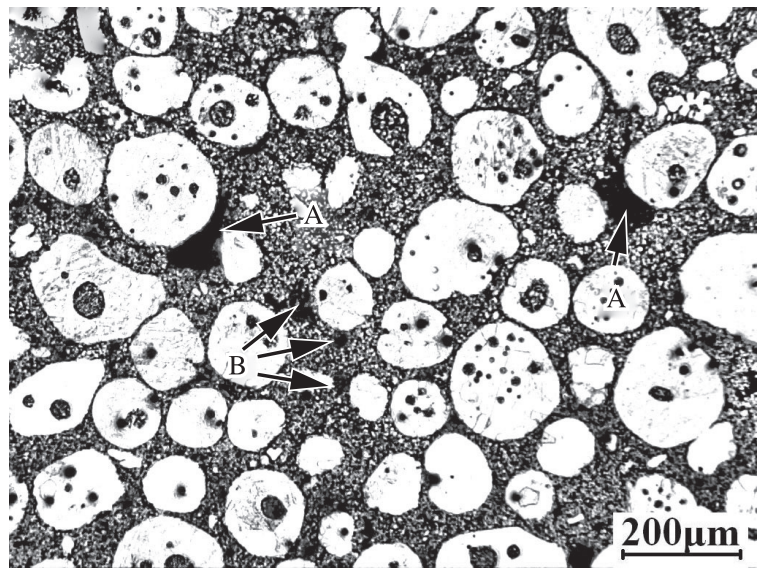

(a)



(b)

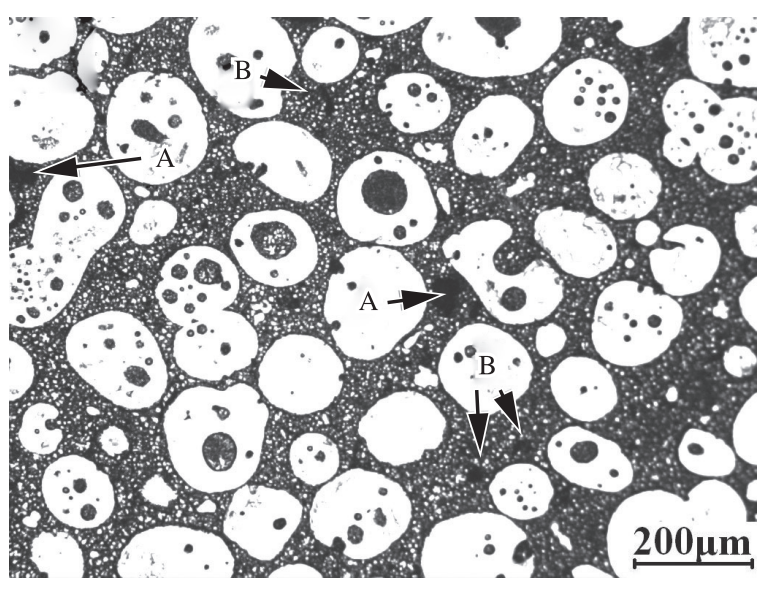

(c)

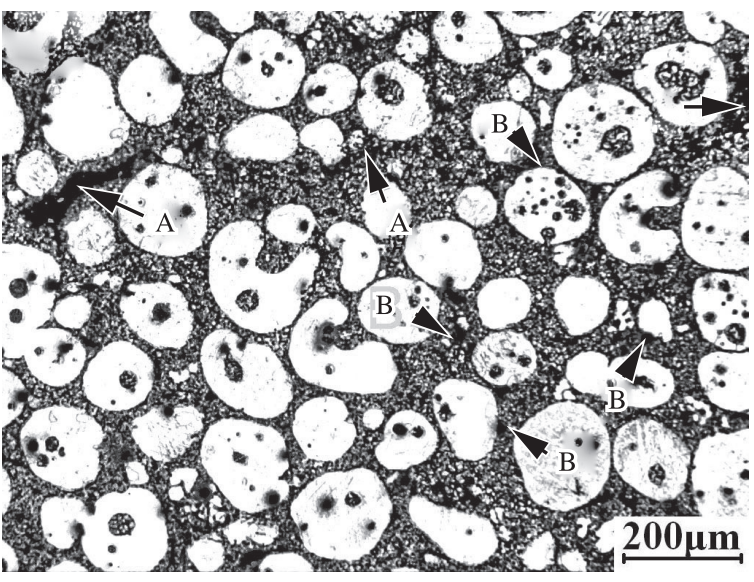

(d)

Figure 2. Microstructures of the thixoformed AM60B alloys under different punch speeds. (a) $1 \mathrm{~m} / \mathrm{s},(\mathrm{b}) 3 \mathrm{~m} / \mathrm{s},(\mathrm{c}) 5 \mathrm{~m} / \mathrm{s}$ and (d) $7 \mathrm{~m} / \mathrm{s}$.

pore amount increases as the speed increases (comparing Figure $2 b, c, d)$. The change in the pore amount can be more clearly seen from the quantitative examination result and corresponding micrographs shown by Figure 3.

It can be suggested that the pores may result from three resources: insufficient mould-filling due to bad flowability of the semisolid slurry, solidification shrinkage after mould-filling and entrapped gas during mould-filling because of turbulent flow. Lower punch speed implies that the time for mould-filling is longer, i.e., the stay time of semisolid ingot in the pressure chamber is longer. However, the chamber temperature $\left(420^{\circ} \mathrm{C}\right)$ is lower than the ingot temperature $\left(610^{\circ} \mathrm{C}\right)$. So it can be expected that the longer the time, the more the amount of solidified liquid phase prior to filling and thus the lower the flowability of the slurry. The lower flowability must generate more cold shuts. In addition, the effective pressure that is exerted to the solidifying slurry after mould-filling is relatively lower due to the higher solid fraction. So a larger number of shrinkage porosities can form because of the resultant worse feeding ability. As the speed increases, both the flowability and feeding ability, especially the flowability become well and thus the pores' number and size decrease and even they disappear. But increasing the speed must cause more and more intensive flow. And thus, more and more gas will be entrapped within the slurry to form more and more gas pores. Based on these standpoints, it can be suggested that the large-sized pores $A$ in Figure 2a should belong to cold shuts and most of the small-sized pores B in Figure 2a, b should be shrinkage porosities, but most of the pores A and B in Figure $2 \mathrm{c}, \mathrm{d}$ can be considered as gas pores.

As shown by Figure 4, it can be seen that the pores' number and size gradually increase in the sequence of regions $\mathrm{A}, \mathrm{B}$ and $\mathrm{C}$. The quantitative examination result is given by Figure 5. Namely, the pores' distribution along the tensile bars is ununiform and their amount gradually increases from the end near the inner gate to the other end. In addition, some large-sized gas pores always exist in the plate part as shown by Figure 6a, especially in that of the products thixoformed under high punch speeds. The reason that causes these results is related to the mould-filling behavior of semisolid slurry. For each tensile bar in one product, the mould filling behavior should be similar. In here, the case of bar B (Figure 6a) is taken as an example to be discussed. As shown by Figure 6b, driven by high pressure, the slurry flows into the cavity in the form of a high-speed stream. This stream shoots towards the end $\mathrm{D}$ along the path marked by the white full-line arrows and forces part of the air in the 


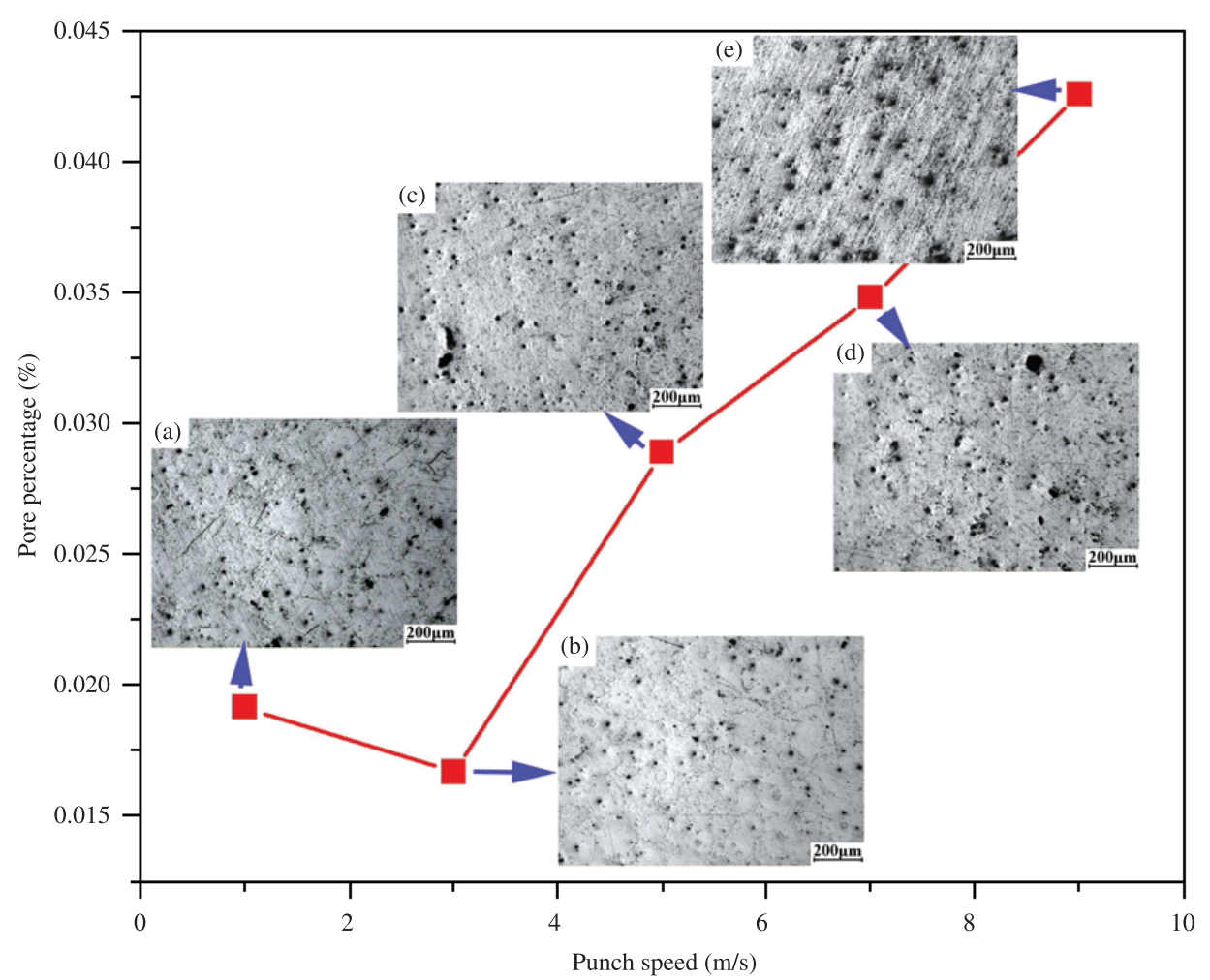

Figure 3. Variation of the pore percentage in position B with punch speed and the corresponding microstructures.

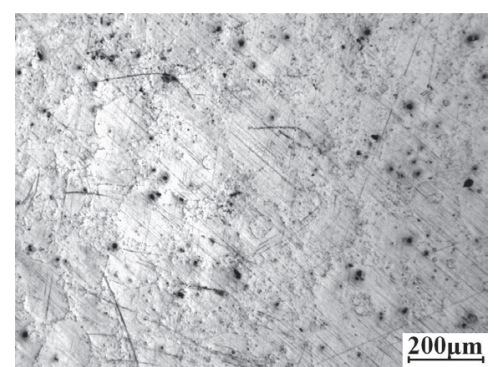

(a)

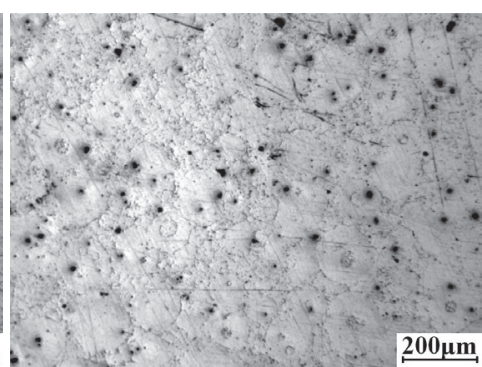

(b)

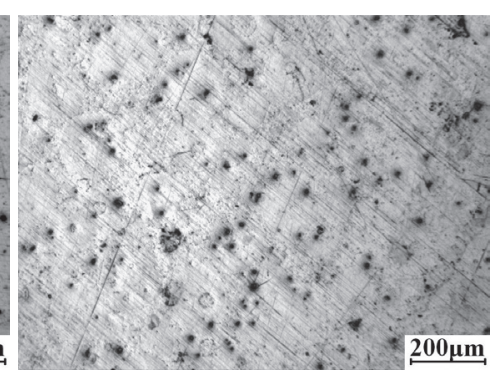

(c)

Figure 4. Microstructures of the different regions of AM60B alloy thixoformed under punch speed of $3 \mathrm{~m} / \mathrm{s}$.

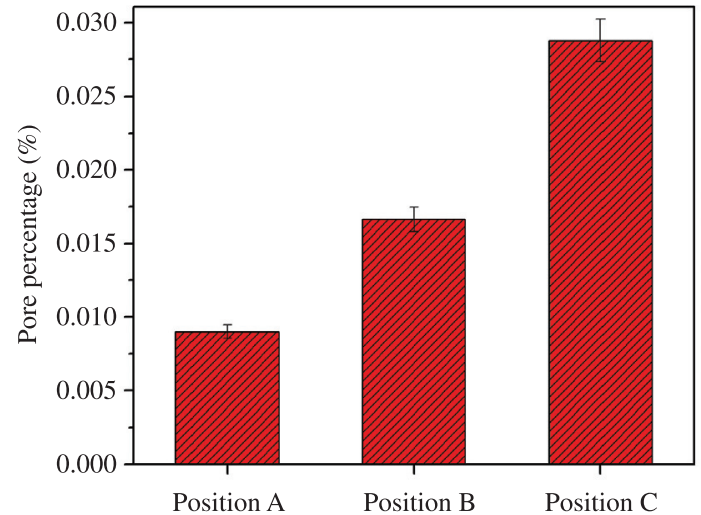

Figure 5. Pore percentages of the different positions of AM60B alloy thixoformed under punch speed of $3 \mathrm{~m} / \mathrm{s}$. bar cavity to flow into the plate cavity. When the stream reaches the end D, part of it continuously flows ahead and enters into the plate cavity, and the other flows backward along the cavity wall (i.e., along the path indicated by the dot-line arrows) due to the reflection of the end D cavity wall. As shown by the "up" arrow, the end D of the mould is upturned during forming. So the gravity direction is towards the end C. Due to the flow resistance and solidification (due to the chilling from the mould, the slurry can solidify during flowing), part of the back-flowing slurry is left in the end $\mathrm{C}$ when it reaches this end, and the other, due to the reflection of the end $\mathrm{C}$ cavity wall, changes the flow direction again and flows along the path indicated by the full-line arrows to the end D together with the stream just shooting from the inner gate. That is to say that a closed circle flowing mode is formed. During circle flowing, some of the slurry is 
always left in the end $\mathrm{C}$ and the bar cavity is gradually fully filled from the end $\mathrm{C}$ to the end $\mathrm{D}$. At the same time, there is always some air in the bar cavity to flow into the plate cavity along with the flowing stream or flow out through the mould parting surface. Some of the air is entrapped by the turbulent circle flow. In view of the filling sequence, the solidification should also carry out from the end $\mathrm{C}$ to the end D. During solidification, some of the entrapped gas bubbles will merge and float up due to solidification and buoyancy. In addition, some of the air in the plate cavity can flow back to the end D because of the more intensive flowing mode in this cavity (it is discussed in the following paragraph). It is just due to these two reasons that a gradient distribution of gas pores is formed in the bars.

For the plate cavity in the mould top, as shown by Figure $6 c$, the slurry flow is more intensive and turbulent due to the reflection of cavity wall and collision of many strands of flow. According to the analysis shown by Figure $6 \mathrm{c}$, at least 11 vortex flows are generated. This implies that at least 11 large-sized gas pores may form. From Figure 6c, only 7 gas pores can be seen with the naked eye in the plate surface. It is expected that more pores can be found using magnifier or the plate is cut openly. That is to say that the air in the plate cavity also can not be completely discharged through air vents and mould parting surface in time, and

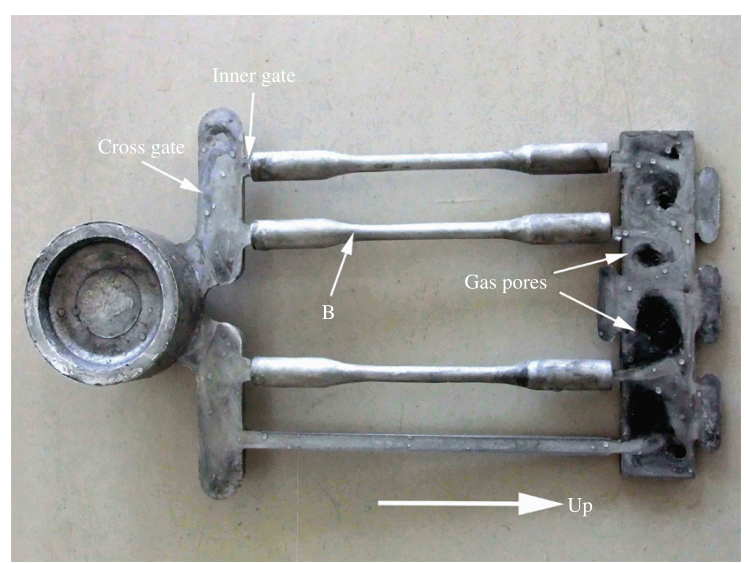

(a)



(b)

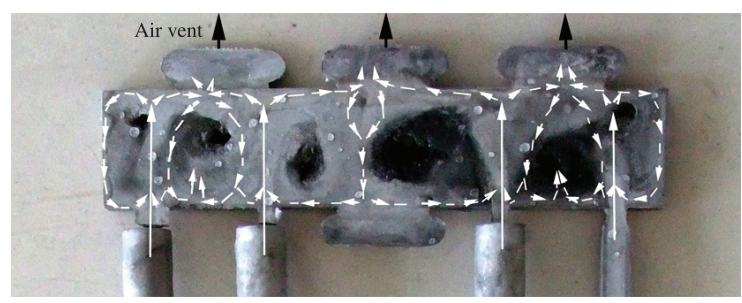

(c)

Figure 6. Photograph of an AM60B product thixoformed under punch speed of $7 \mathrm{~m} / \mathrm{s}$, (b) and (c) schematics of the slurry flow behavior in the bar cavity and plate cavity during forming. thus many gas pores are generated. In addition, the intensive vortex flows with high speed must result in high pressure in the cavity. But in the bar cavities, the pressure may be relatively lower as a result of the flow stream shooting into the plate cavity. So some of the air in the plate cavity may flow backwards the end D of the bar cavity.

Based on the flowing behaviors during mould-filling discussed above, it can be reasonably proposed that the higher the punch speed, the more intensive the turbulent flow, thus the more the entrapped air amount and the more the gas pores in the final product. To decrease or eliminate gas pores, the turbulent flow or vortex flow should be weakened or eliminated. In the present work, the turbulent flow is the weakest at the punch speed of $3 \mathrm{~m} / \mathrm{s}$.

Figure 7 shows the variation of UTS with the punch speed. It indicates that the UTS increases as the punch speed increases and is up to a peak value at $3 \mathrm{~m} / \mathrm{s}$, then continuously decreases. This change tendency is completely consistent to that of the pore amount: the higher the pore amount, the lower the UTS. From Figure $8 \mathrm{a}$, it can be seen that the fracture surface of the alloy formed under punch speed of $1 \mathrm{~m} / \mathrm{s}$ is characterized by a large-sized pore (cold shut or shrinkage porosity). This further implies that the mould-filling ability and shrinkage-feeding ability are quite low at the speed of $1 \mathrm{~m} / \mathrm{s}$. As the punch speed increases, the features of cold shut or porosity gradually disappear and lots of dimples that are characterized by plastic deformation are formed when the speed increases to $3 \mathrm{~m} / \mathrm{s}$ (Figure 8b). As known from the above discussion, this is because the microstructure compactness is enhanced due to the improvements of mold-filling capacity and feeding ability. But when the speed exceeds $3 \mathrm{~m} / \mathrm{s}$, large-sized pores appear again and both their number and size increase with the speed due to the strengthening turbulent flow (comparing Figure 8c, d). From either the metallograph or the fractograph, the microstructure of the alloy formed under speed of $3 \mathrm{~m} / \mathrm{s}$ is the most compact and thus its UTS is the highest (Figure 7).

Figure 9 gives the fracture surface side-views of the alloys thixoformed under different punch speeds. It shows that the fracture path during tensile testing is always along the secondarily solidified structure between the primary

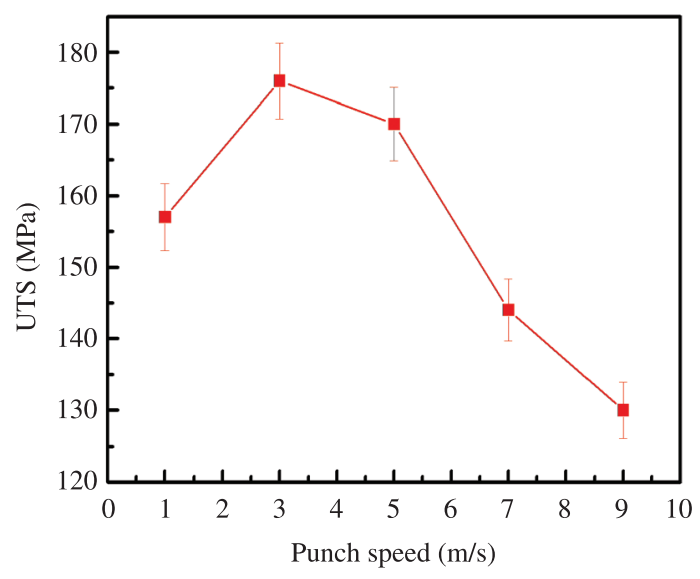

Figure 7. Variation of UTS with punch speed. 


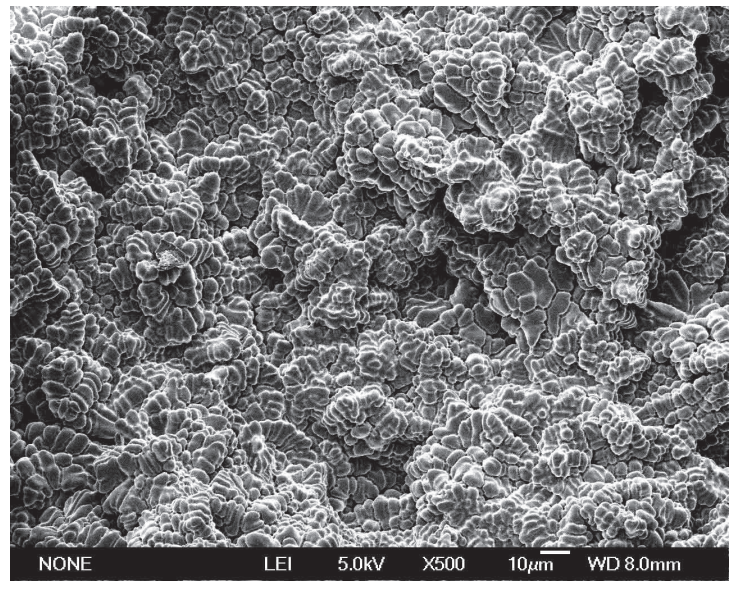

(a)

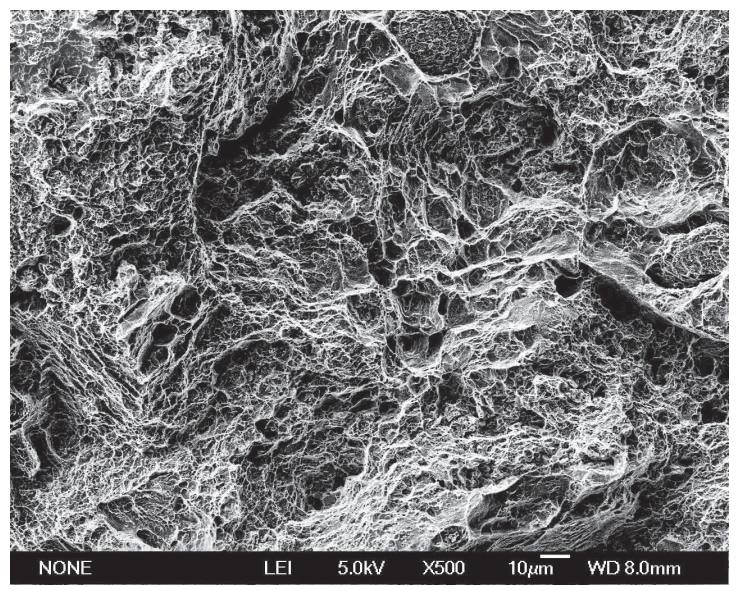

(c)

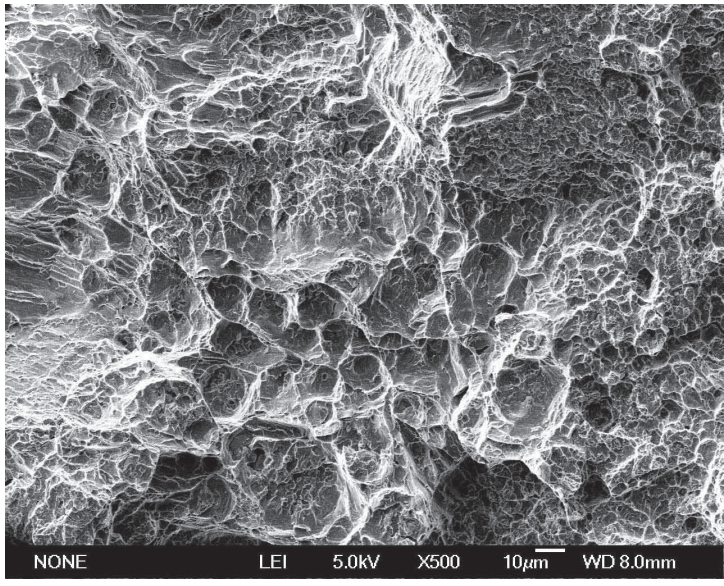

(b)

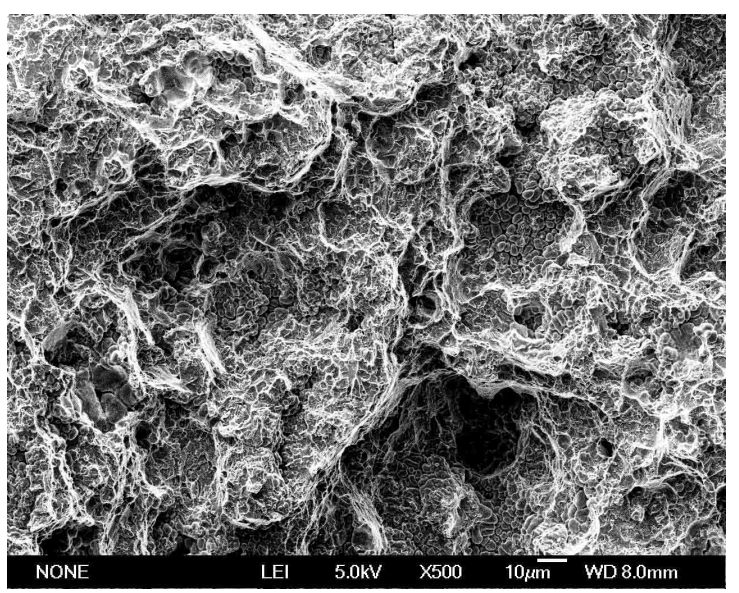

(d)

Figure 8. Fractographs of the AM60B alloy thixoformed under punch speed of (a) $1 \mathrm{~m} / \mathrm{s}$, (b) $3 \mathrm{~m} / \mathrm{s}$, (c) $5 \mathrm{~m} / \mathrm{s}$ and (d) $7 \mathrm{~m} / \mathrm{s}$.

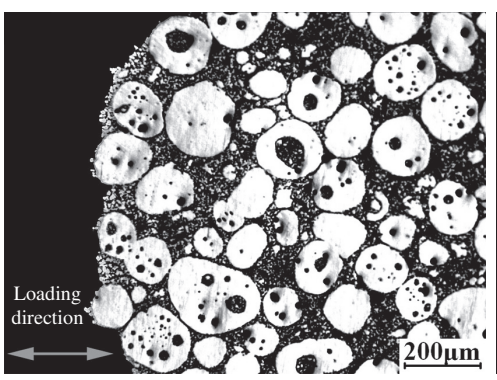

(a)

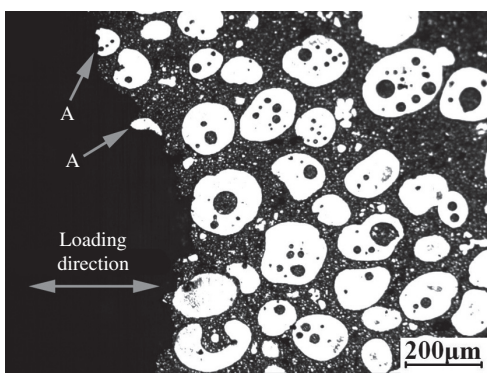

(b)

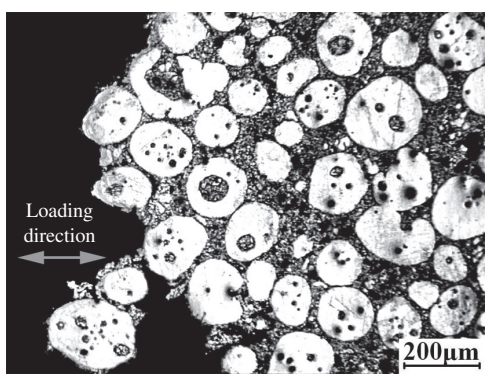

(c)

Figure 9. Fracture surface side-views of the AM60B alloy thixoformed under punch speed of (a) $1 \mathrm{~m} / \mathrm{s}$, (b) $3 \mathrm{~m} / \mathrm{s}$ and (c) $7 \mathrm{~m} / \mathrm{s}$.

particles, regardless of the punch speed. But for the alloy formed under speed of $3 \mathrm{~m} / \mathrm{s}$, as shown by arrows in Figure $9 \mathrm{~b}$, the fracture across the primary particles can be frequently found (marked by A). According to the above discussion, there are always a large number of pores in the secondarily solidified structure. In addition, the other casting defects, such as oxidation inclusions and small-sized invisible porosities, should also exist in this structure. So the secondarily solidified matrix is the weak point of this alloy and thus the fracture path is preferentially chosen within it. This result is similar to those of thixoformed zinc, aluminium and the other magnesium based alloys ${ }^{16-20}$. But when the compactness of the secondarily structure is improved, the fracture may be frequently across the primary particles in some local zones. However, it should be noted that the dominative fracture path can not be altered in view of the available results about thixoformed alloys ${ }^{16-20}$.

Based on the above discussion, it can be concluded that the punch speed has large effect on the pore amount (number and size) in the thixoformed AM60B alloy and thus on its UTS. At low speed, the pores are mainly composed of large-sized cold shuts and porosities due to insufficient 




(a)

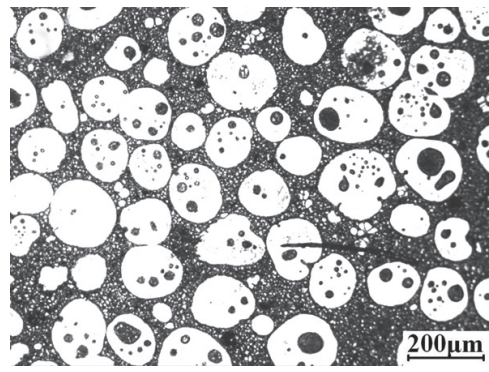

(b)



(d)

Figure 10. Microstructures of the thixoformed AM60B alloy under different heating durations. (a) 90 minutes, (b) 110 minutes and (c) 150 minutes.

mould-filling capacity and bad shrinkage-feeding ability, but at high speed, the pores mainly belong to gas pores resulted from the intensive turbulent flow. To obtain a product with compact microstructure, choosing an adequate punch speed is very important. For the present work, the speed of $3 \mathrm{~m} / \mathrm{s}$ is the most adequate one. The secondarily solidified structure is the weak point of this formed alloy and the fracture path is always along this structure during tensile testing, regardless of the punch speed.

\subsection{Effect of reheating time}

Figure 10 presents the microstructures of the alloys thixoformed under different reheating durations at $610{ }^{\circ} \mathrm{C}$. It shows that the reheating duration has obvious effects on the primary particle fraction and size: the primary particle size increases while the fraction decreases with the increase in reheating time. These changes can be more clearly seen from the quantitative examination results shown by Figure 11. Because the dimensions of the used start ingots are relatively large $(\Phi 70 \mathrm{~mm} \times 112 \mathrm{~mm})$, it needs long time for the temperature of every position in the ingot, especially the center region, to reach the given $610^{\circ} \mathrm{C}$ during reheating. In addition, the microstructure evolution during reheating is slightly laggard than the temperature rise ${ }^{21}$. So the liquid fraction and thus the amount of the resultant secondarily solidified structure increases (i.e., the primary particle fraction decreases) as the reheating time prolongs. In addition, driving by decreasing solid/liquid interface energy, the primary particles will grow up through coalescence and Ostwald ripening during reheating ${ }^{21,22}$, resulting in the formation of large primary particles in the formed alloy.

The pore amounts of the alloys thixoformed under different reheating durations and corresponding microstructures are given by Figure 12. It indicates that the pore size decreases as the heating time prolongs and increases again when the time exceeds 130 minutes (comparing Figure 12a, b), and thus the resulting total pore amount also changes in such a manner. The facture surface morphologies also show this manner: some large-sized pores always exist in the surface of the alloy formed under short heating duration (Figure 13a), and their size gradually decreases as the duration extends and even no obvious pores can be found when the time is prolonged to 130 minutes (Figure 8b); after that, the pores can be clearly seen again (Figure 13b). It is known that the most important advantage of thixocasting, i.e., reduction of shrinkage porosities and



Figure 11. Variations of primary particle fraction and size with heating duration.

gas pores, can not be enough played until the semisolid slurry has a given relatively high solid fraction $(0.4-0.6)^{3,4}$. If the fraction is too low, gas pores can easily form because of intensive turbulent flow, but when the fraction is too high, cold shuts or large-sized pores can form due to insufficient filling. So it can be suggested that the pores, especially the large-sized pores formed under the short time are cold shuts, and their size decreases due to the improvement of flowability as the time (also the liquid fraction) prolongs; but when the time exceeds 130 minutes, the gas pores will dominate and their size also increases due to more intensive turbulent flow resulted from too high liquid fraction.

Figure 14 shows the variation of UTS with the reheating time. It means that the UTS continuously increases as the heating time prolongs and is up to a peak value at 130 minutes, and then decreases. Based on the above discussion on the pore size and amount, the UTS changed in such a manner can be easily explained. In addition, it can be found that the effects of primary particle size and fraction on the UTS are smaller than that of the pore amount. But the reheating time is also an important parameter for achieving a product with compact microstructure. This is especially crucial for the reheating using resistance furnace because it needs relatively long time for large-sized ingots. In this work, the reheating of 130 minutes at $610^{\circ} \mathrm{C}$ is adequate. Finally, it should be noted that the reheating time also does not alter the fracture path during tensile testing. 


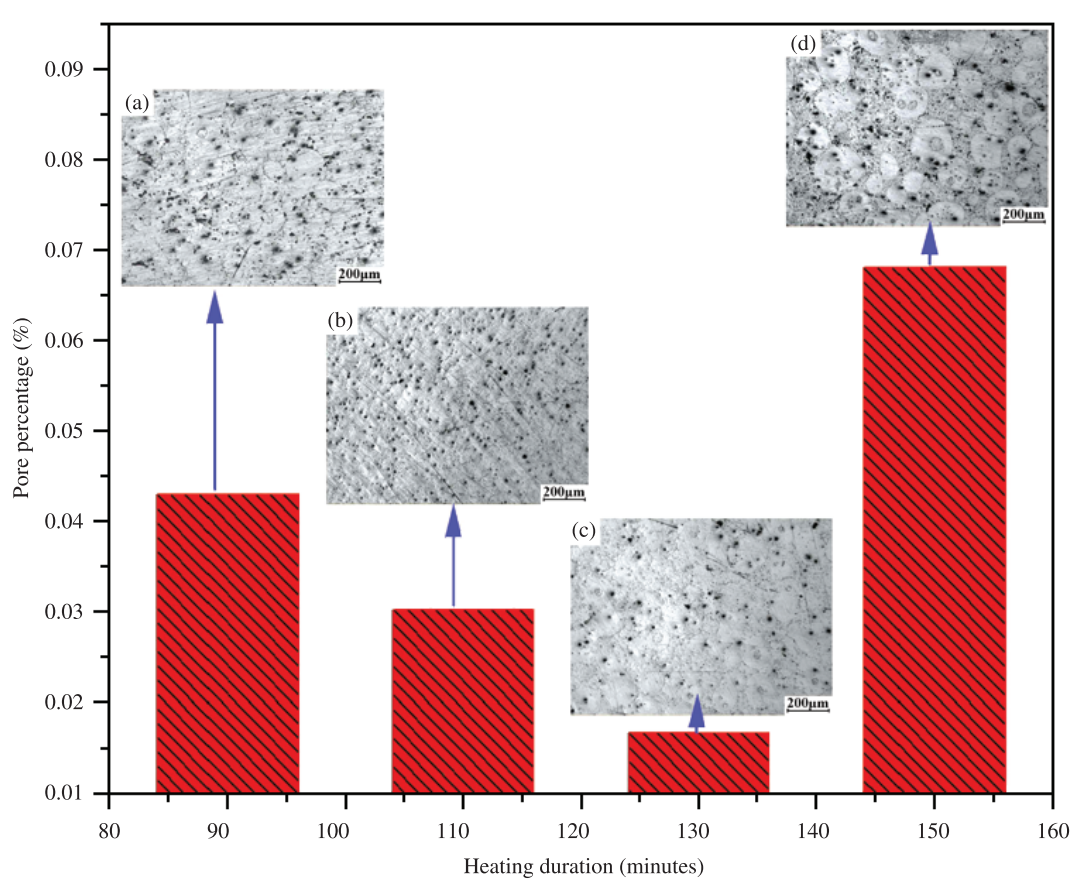

Figure 12. Pore percentages of the AM60B alloy thixoformed under different heating durations and the corresponding microstructures.



(a)



(b)

Figure 13. Fractographs of the AM60B alloy thixoformed under heating durations of (a) 90 minutes and (b) 150 minutes.

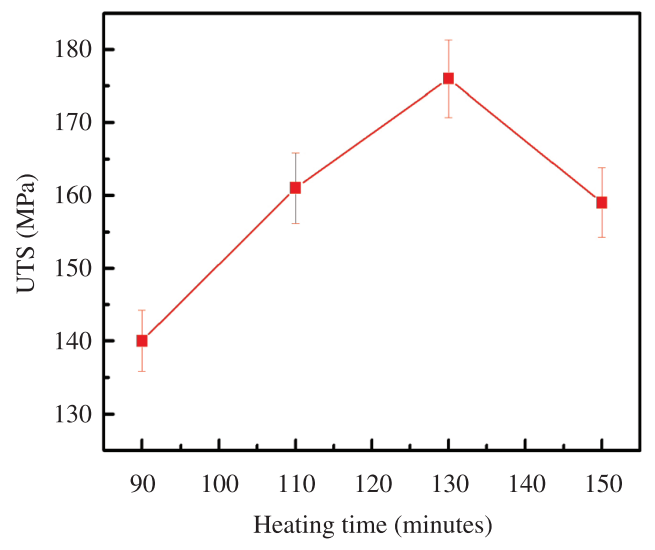

Figure 14. Variation of UTS with heating duration at $610{ }^{\circ} \mathrm{C}$.
So it can be suggested that the reheating time has obvious effect on the microstructure, especially the pore amount of the formed alloy, and thus on the UTS. There is an optimal reheating time and shorter or longer time can decrease the microstructure compactness. But this time does not change the facture path during tensile testing.

\subsection{Effect of reheating temperature}

As shown by Figures 15 and 16, similar to the effect of reheating duration, the reheating temperature also has large effect on the primary particle size and fraction and its effect on the particle fraction is larger than that of the duration (comparing Figures 11 and 16). It can be seen that the primary particle fraction decreases from $56 \%$ to $37 \%$ when the temperature is elevated from $600{ }^{\circ} \mathrm{C}$ to $620^{\circ} \mathrm{C}$. The primary particle size first decreases and then increases when 


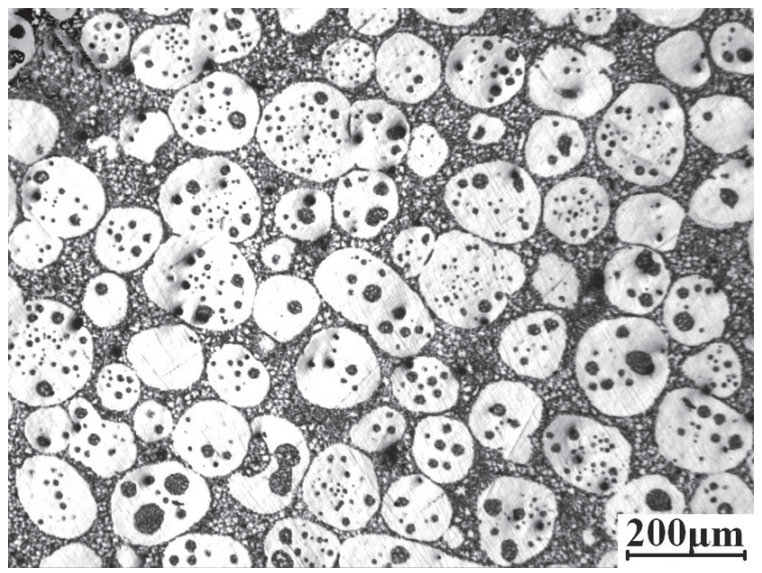

(a)

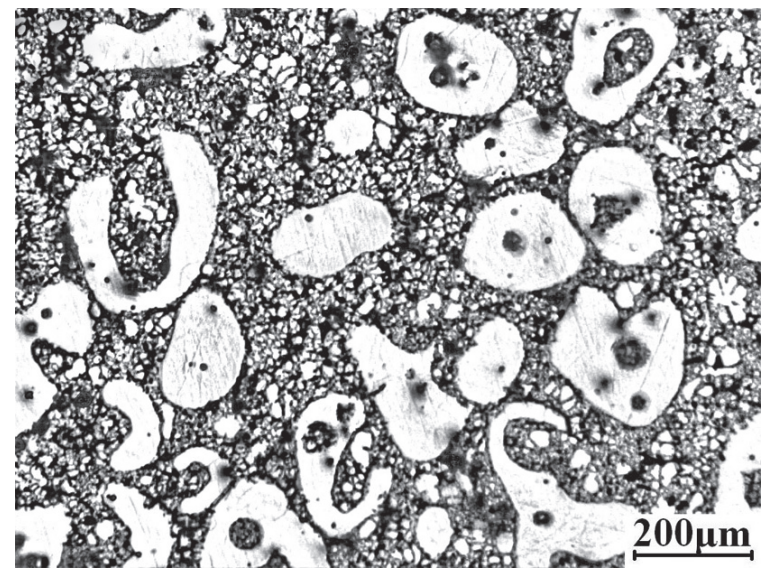

(b)

Figure 15. Microstructures of the AM60B alloy thixoformed under heating temperatures of (a) $600{ }^{\circ} \mathrm{C}$ and (b) $620{ }^{\circ} \mathrm{C}$.

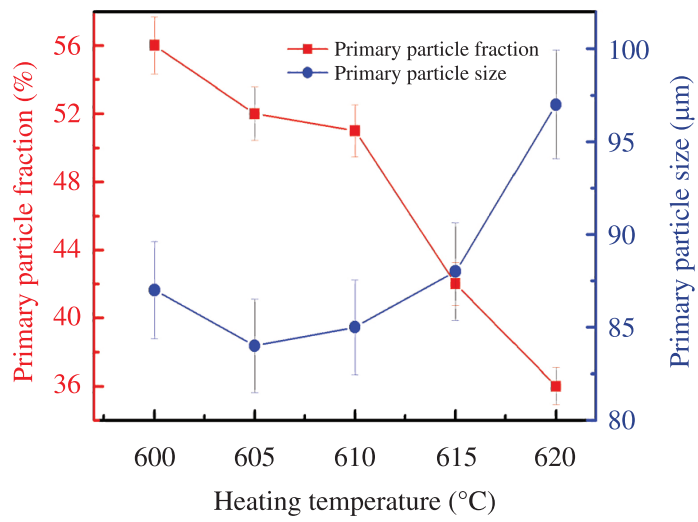

Figure 16. Variations of primary particle fraction and size with heating temperature.

the temperature exceeds $605^{\circ} \mathrm{C}$. Figure 15 also shows the temperature significantly affects the particle morphologies.

It can be easily understood that raising the reheating temperature can decrease the primary particle fraction. But for the primary particle size, its variation closely depends on the effect of reheating temperature on the microstructural evolution during reheating. The microstructural evolution of AM60B alloy includes four stages: the initial rapid coarsening, structure separation, spheroidization and final coarsening ${ }^{13,21}$. From the above section, it is known that the liquid faction during the heating period of 130-150 minutes still increases, which implies that the semisolid system does not reach its equilibrium solid-liquid state when heated for 130 minutes, i.e., the system is in the spheroidization stage. During this stage, the decrease of primary particle size due to partial melting and the increase due to coalescence and Ostwald ripening are in a competitive state. As the reheating temperature rises, both the coalescence and Ostwald ripening are significantly enhanced because of the increases of solid/liquid interface energy and atom diffusion ability although the melted parts of the particles also increase, i.e., the size increase rate is higher than the size decrease rate ${ }^{13,21}$. So the primary particle size increases as the temperature rises. In addition, it can be expected that the coarsening of the entrapped liquid pools within the primary particles is also enhanced by the temperature rise, and thus they evolve from many small dispersive pools into one large central pool (comparing Figures 15a, b). Simultaneously, a marginal local zone of some of particles melt to form a gap and the particles then become into the worm-like irregular structures (Figure 15b).

Figure 17 shows the variation of pore amount with the reheating temperature and the corresponding microstructures. It indicates that there is an optimum temperature of $610{ }^{\circ} \mathrm{C}$, and lower or higher temperature will increase the pore amount. As described above, the heating temperature has large effect on the liquid fraction of semisolid slurry. Lower temperature generates less liquid and thus cold shuts or shrinkage porosities can easily form due to insufficient filling or bad shrinkage feeding. But higher temperature generates more liquid and gas pores can easily form because of more intensive turbulent flow. The fractographs show that there is a large-sized cold shut or porosity on the facture surface of the alloy formed at the lowest reheating temperature of $600{ }^{\circ} \mathrm{C}$ (Figure 18a) while there are many relatively small-sized gas pores on the surface of the alloy formed at the highest temperature of $620{ }^{\circ} \mathrm{C}$ (Figure 18b). Figure 19 shows the variation of UTS with the reheating temperature. This change can be easily understood in view of the pore amount change. Similarly, the present result also indicates that the reheating temperature does not change the fracture path.

Therefore, it can be concluded that the reheating temperature can not only significantly affect the primary particle size, morphology and fraction, but also the microstructure compactness of the formed product. There is an optimum temperature of $610^{\circ} \mathrm{C}$ and lower or higher temperature will result in the increase of pore amount, and thus decrease the UTS. The reheating temperature has no effect on the fracture path. So far, an appropriate thixoforming technique of AM60B alloy can be obtained, reheating for 130 minutes at $610{ }^{\circ} \mathrm{C}$ and subsequent 




Figure 17. Variation of pore percentage in position A with heating temperature and the corresponding microstructures.



(a)

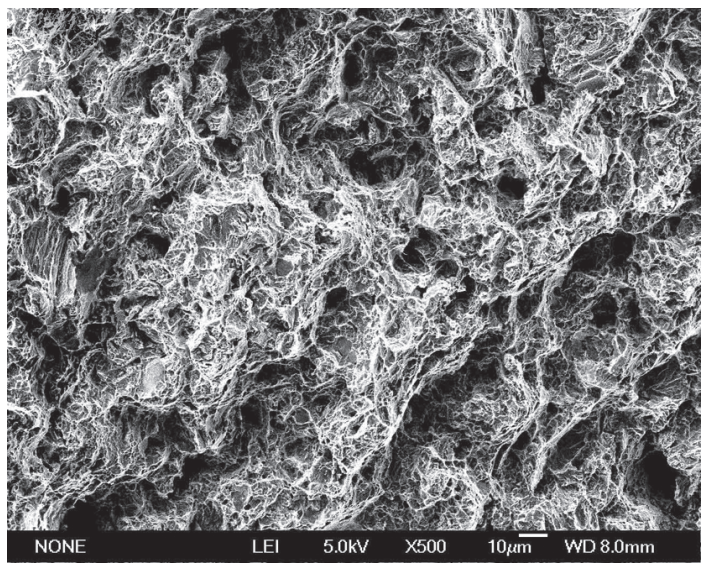

(b)

Figure 18. Fractographs of the AM60B alloy thixoformed under heating temperatures of (a) $600{ }^{\circ} \mathrm{C}$ and (b) $620^{\circ} \mathrm{C}$.

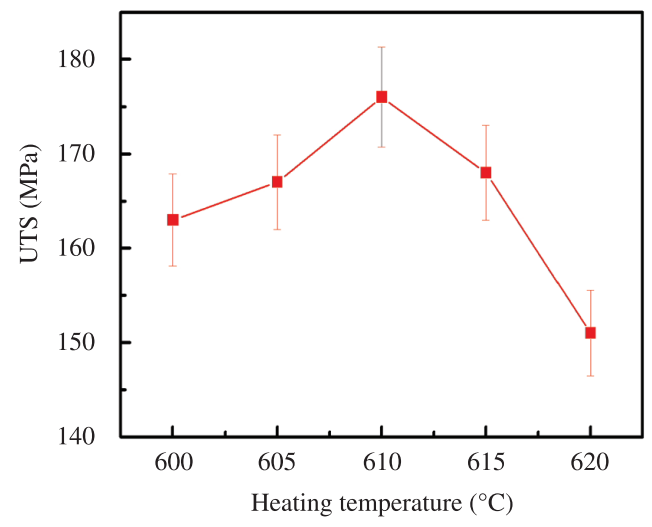

Figure 19. Variation of UTS with heating temperature. thixoforming in a punch speed of $3 \mathrm{~m} / \mathrm{s}$, in view of the microstructure compactness and UTS.

\section{Conclusions}

In view of the microstructure compactness and UTS, an appropriate thixoforming technique of AM60B alloy has been developed, reheating for 130 minutes at $610{ }^{\circ} \mathrm{C}$ and subsequent thixoforming in a punch speed of $3 \mathrm{~m} / \mathrm{s}$;

The punch speed during thixoforming of AM60B magnesium alloy has large effect on microstructure compactness. Cold shuts or shrinkage porosities always form at low speed while gas pores easily generate at high speed; 
Similarly, short reheating duration or low reheating temperature often produces cold shuts or porosities and long duration or high temperature frequently generates gas pores. In addition, these two parameters have obvious effects on the primary particle size, fraction and morphology;

Due to their effects on the formation of pores (cold shuts, porosities and gas pores), they significantly affect the UTS of the formed alloy. But they have no effect on the fracture path during tensile testing and the path is always along the secondarily solidified structure between the primary particles; and

\section{References}

1. Easton M, Beer A, Barnett M, Davies C, Dunlop G and Durandet Y. Magnesium alloy applications in automotive structures. JOM. 2008; 60:57-62. http://dx.doi.org/10.1007/ s11837-008-0150-8

2. Eliezer D, Aghion E and Froes FH. Magnesium science, technology and applications. Advanced Performance Materials. 1998; 5:201-212. http://dx.doi. org/10.1023/A:1008682415141

3. Fan Z. Semisolid metal processing. International Materials Review. 2002; 47:49-85. http://dx.doi. org/10.1179/095066001225001076

4. Atkinson HV. Semisolid processing of metallic materials. Materials Science Technology. 2010; 26:1401-1413. http:// dx.doi.org/10.1179/026708310X12815992418012

5. Czerwinski F, Zielinska A, Pinet P J and Overbeeke J. Correlation of microstructure and tensile properties of a thixomoulded AZ91D magnesium alloy. Acta Materialia. 2001; 49:1225-1235. http://dx.doi.org/10.1016/ S1359-6454(01)00015-5

6. Zhang QQ, Cao ZY, Liu YB, Zhang YF, Zhang L, Zhang ML et al. Effect of asymmetrical deformation on the microstructure evolution of semisolid AZ91D alloy. Materials Science and Engineering A. 2008; 488:260-265. http://dx.doi. org/10.1016/j.msea.2007.12.002

7. Wang JG, Lin HQ, Wang HY and Jiang QC. Effects of different processing parameters on the semisolid microstructure of the AZ91D alloy during partial remelting. Journal of Alloys and Compounds. 2008; 466:98-105. http://dx.doi.org/10.1016/j. jallcom.2007.11.030

8. Ji ZS, Hu ML, Sugiyama S and Yanagimoto J. Formation process of AZ31B semi-solid microstructures through straininduced melt activation method. Materials Characterization. 2008; 59:905-911. http://dx.doi.org/10.1016/j. matchar.2007.07.015

9. Wang HY, Zha M, Liu B, Wang DM and Jiang QC. Microstructural evolution behavior of $\mathrm{Mg}-5 \mathrm{Si}-1 \mathrm{Al}$ alloy modified with $\mathrm{Sr}-\mathrm{Sb}$ during isothermal heat treatment. Journal of Alloys Compounds. 2009; 480:L25-28. http://dx.doi. org/10.1016/j.jallcom.2009.02.044

10. Nami B, Shabestari SG, Miresmaeili SM, Razavi H and Mirdamadi S. The effect of rare earth elements on the kinetics of the isothermal coarsening of the globular solid phase in semisolid AZ91 alloy produced via SIMA process. Journal of Alloys Compounds. 2009; 489:570-575. http://dx.doi. org/10.1016/j.jallcom.2009.09.112

11. Zhao ZD, Chen Q, Kang F and Shu DY. Microstructural evolution and tensile mechanical properties of thixoformed
The effect of pore amount on the UTS is lager than those of the primary particle size, fraction and morphology.

\section{Acknowledgement}

The authors wish to express thanks to financial support from the National Basic Research Program of China (Grant N ${ }^{\circ}$. G2010CB635106), the Program for New Century Excellent Talents in University of China (Grant $\mathrm{N}^{\circ}$. NCET-10-0023) and the Program for Hongliu Outstanding Talents of Lanzhou University of Technology.

AZ91D magnesium alloy with the addition of yttrium. Journal of Alloys Compounds. 2009; 482:455-467. http://dx.doi. org/10.1016/j.jallcom.2009.04.059

12. Zhao ZD, Chen Q, Chao HY and Huang SH. Microstructural evolution and tensile mechanical properties of thixoforged ZK60-Y magnesium alloys produced by two different routes. Materials and Design. 2010; 31:1906-1916. http://dx.doi. org/10.1016/j.matdes.2009.10.056

13. Chen TJ, Ma Y, Wang RQ, Li YD and Hao Y. Microstructural evolution during partial remelting of AM60B magnesium alloy refined by $\mathrm{MgCO}_{3}$. Transactions of Nonferrous Metal Society of China. 2010; 20:1615-1621. http://dx.doi.org/10.1016/ S1003-6326(09)60348-4

14. Chen CP and Tsao C-YA. Semi-solid deformation of aluminum alloy 356 with non-dendritic structure. Materials Science and Technology. 1999; 15:981-985.

15. Chen CP and Tsao C-YA. Semi-solid deformation of non-dendritic structures -I. phenomenological behavior. Acta Materialia. 1997; 45:1955-1968. http://dx.doi.org/10.1016/ S1359-6454(96)00312-6

16. Chen TJ, HaoY, Sun J and LiYD. Effects of processing parameters on tensile properties and hardness of thixoformed ZA27 alloy. Materials Science and Engineering A. 2004; 382:90-103. http:// dx.doi.org/10.1016/j.msea.2004.04.029

17. Park C, Kim S, Kwon Y, LeeY and Lee J. Effect of microstructure on tensile behavior of thixoformed 357-T5 semisolid Al alloy. Metallurgy and Materials Transactions A. 2004; 35:1407-1410. http://dx.doi.org/10.1007/s11661-004-0316-0

18. Du X and Zhang E. Microstructure and mechanical behavior of semi-solid die-casting AZ91D magnesium alloy. Materials Letter. 2007; 61:2333-2337. http://dx.doi.org/10.1016/j. matlet.2006.09.007

19. Kleiner S, Beffort O, Wahlen A and Uggowitzer PJ. Microstructure and mechanical properties of squeeze cast and semi-solid cast Mg-Al alloys. Journal of Light Metals. 2002; 2:277-280. http://dx.doi.org/10.1016/ S1471-5317(03)00012-9

20. Boostani AF and Tahamtan S. Effect of a novel thixoforming process on the microstructure and fracture behavior of A356 aluminum alloy. Materials and Design. 2010; 31:3769-3776. http://dx.doi.org/10.1016/j.matdes.2010.03.019

21. Chen TJ, Lv WB, Ma Y, Huang H J and Hao Y. Semisolid microstructure of AM60 magnesium alloy refined by SiC particles. International Journal of Materials Research. 2011; 102:14591467. http://dx.doi.org/10.3139/146.110612 